\title{
A Study to Assess the Prevalence of Community Mental Health Problems of Jenela Wereda Kebele 14,Harrar Town in Eastern Ethiopia 2017
}

\author{
Bahubali J G, Sumesh K, Sanjay T and Solomon Moges* \\ School of Nursing and Midwifery, College of Health and Medical Sciences, Haramaya University, Harrar, Ethiopia
}

Submission: December 09, 2018; Published: March 20, 2018

*Corresponding author: Solomon Moges, Assistant Professor, School of Nursing and Midwifery, College of Health and Medical Sciences, Haramaya University, Harrar, Ethiopia, Email: thomassanjay994@gmail.com

\begin{abstract}
Mental health is a major problem of many people's worldwide. Conditions affecting the brain are an important cause of disability and have a major impact on quality of life as well as on the social and economic viability of families and communities. In Ethiopia, mental illness is the leading non communicable disorder in terms of burden. The disability and mortality associated with mental illness in Ethiopia is high. This study concludes the following prioritized problems in the community that needs interventions. Which includes Lack of awareness towards mental illness (78.4\%), Lack of awareness towards epilepsy (41.75\%), Presence of common mental disorders (6.76\%),Prevalence of stressful life event (34.87\%) and Prevalence of substance use (alcohol 31.44\%). Health is defined as a state of complete physical, mental and social wellbeing and not merely the absence of disease or infirmity (WHO, 2001).Mental health is defined as a state of well-being in which every individual realizes his or her own potential, can cope with the normal stressors of life, can work productively and fruitfully, and is able to make a contribution to her or his community (WHO, 2014).Common mental disorder (CMD) is a term used to describe a group of mental disorders that frequently occur in primary care patients. It includes symptoms of depression, anxiety and somatization the latter often indicated by repeated visits to health care practitioners without resolution of the problem.
\end{abstract}

\section{Introduction}

Mental illness comprised $13 \%$ of the total global burden of disease in 2000 , a figure that is expected to rise to $15 \%$ by the year 2020. Mental health problem is recognized as a public health problem in developed as well as developing countries. The notion that mental health problems are less common in low-income countries than in developed countries has long been disputed. No fewer than 20 million people around the globe suffer from epilepsy which is also a mental disorder; and a further 200 million are incapacitated by less severe mental and neurological disorders such as neuroses and peripheral neuropathy (Dr. Kesetebirhan Admasu (Federal Democratic Republic of Ethiopia Ministry of Health, National Mental Health Strategy), 2012/13 - 2015/16, and Amare Deribew et al. [1-10].

The objectives of the study is to assess awareness, attitude and practice of the community on mental health and its related problems and Epilepsy as well as their magnitude in kebele 14, Jenela wereda Harar town, Eastern Ethiopia 2017.The study was conducted by using Community based cross-sectional study design and probability systematic random sampling technique, until the required sample size of 281 was attained. The data was collected by using a structured, pre designed questionnaire from March-April 2017. The questionnaires include basic demographic information, mental health problems, psychosocial stressors, clinical factors, epilepsy, substance and SRQ-20 for common mental health disorder. The finding of the study includes 281 households in our sample among this about $46.3 \%$ (432) are male and 53.7\% (501) are Female, about 933 individuals among are Muslims 25.30\%(236),65.59\%(612) are orthodox,8.47\%(79) are protestant, $0.64 \%(6)$ are other religious followers. The educational status categories $93(9.97 \%)$ are unable to read and write, $37(3.97 \%)$ are able to read and write but not formally educated, 331(35.48\%) are KG to elementary school, 290(31.08\%) are secondary and preparatory school, $182(19.5 \%)$ are diploma, degree and above. Among this 114(12.22\%) are unemployed, $102(10.93 \%)$ are Government employed,117(12.54\%) are private employed ,1(0.11\%)are NGO employed, 26(2.79\%)are Daily laborer, 293(31.4\%) are student, 138(14.79\%) are Housewife, 95(10.18\%) are Merchant, 47(5.04\%)are others not specified. The marital status categories shows $377(39.76 \%)$ are married, $362(38.8 \%)$ are single, $36(3.86 \%)$ are divorced, $30(3.22 \%)$ are widowed and $34(14.36 \%)$ are not enough for marriage [11-18].

Among 281 respondent recent awareness of mental illness and mental health status reported 61(18.94\%) of them perceived as hereditable and $220(78.29 \%)$ believed that it is not hereditable.243(86.48\%) of the respondents believed mental 
illness as treatable and the remaining respondents 38 (13.52\%) believed as it is not treatable. Among those who believes mental illness is treatable, $194(75.49 \%)$ of the respondents know modern medication, 60(23.35\%) were known traditionalist by means of Holy water and praying. Among the respondents, about
$3(1.17 \%)$ were perceived seclusion and restraints are the means of treatment. $30(10.68 \%)$ of the respondent believed that mental illness is contagious and the remaining 251(89.32\%) of the respondent believed that mental illness is not contagious [19-25] (Figure 1).

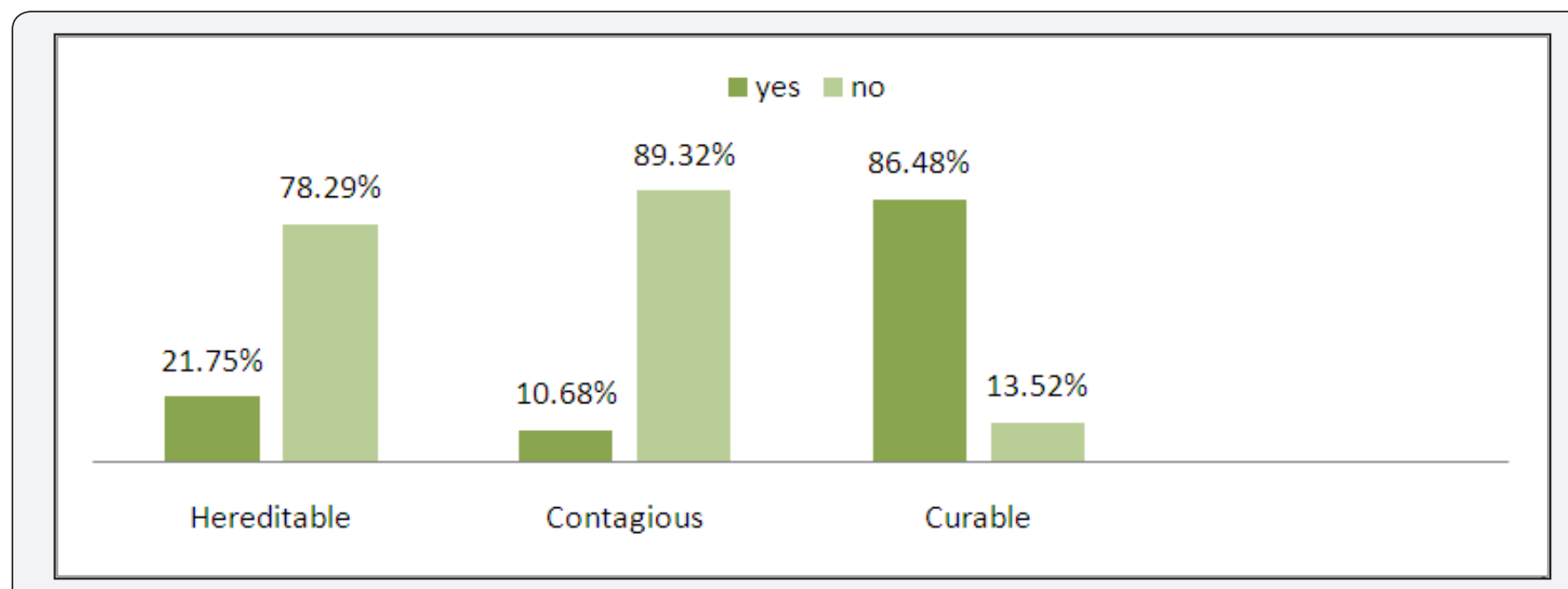

Figure 1: Perception of the community towards mental illness in Harar, Jenela wereda, kebele 14, 2017.

According to our study out of 281 households ,who are interviewed for the presence of stressful life event, $23(9.34 \%)$ was suffered from chronic illness, physical injury or an assault in the last 6 months, $25(10.16 \%)$ of them have close relatives who faced chronic illness, physical injury, or an assault, $20(8.13 \%)$ of them faced death of family members, $41(16.6 \%)$ of them faced loss of loved one or close relatives,15(6.09\%) of them have separation due to marital difficulties, $18(7.31 \%)$ have broken off steady friendship, $20(8.13 \%)$ have serious problem with friends, neighbors or relatives, $23(9.34 \%)$ have a major financial crisis, $22(8.94 \%)$ have lost or stolen materials which they give great value,17(6.91\%) have problems with the police or court, $17(6.91 \%)$ have loss of job or faced difficulty to work, $5(2.03 \%)$ have violence towards them from other in the last 6 months. The magnitude of chronic medical illness, out of 281 respondents $7.8 \%$ peoples has chronic medical illness and the rest $92.2 \%$ has no chronic medical illness. 235(83.63\%) have awareness about epilepsy and only 46(16.37\%) have no awareness about epilepsy. Among the samples who are interviewed for their life time substance use $48.03 \%$ chewing chat while $31.44 \%$ drink alcohol, $19.65 \%$ smoking cigarette, $0.43 \%$ uses cocaine and $0.43 \%$ uses cannabis. Out of 187 substance users who are interviewed for their substance use within the last three months $50.8 \%$ chewing chat while $32.08 \%$ drink alcohol, $16.57 \%$ smoking cigarettes and $0.53 \%$ uses cannabis. Among the samples who are interviewed for CMD symptoms 19 (6.76\%) of individual fulfill the cut off symptom of CMD (six or above). And 129(45.91\%) of interviewed individuals have some symptom CMD which does not touch the cutoff point of CMD. However the remaining 152(54.09\%) individuals never complain the symptom of CMD. Among the symptom of $\mathrm{CMD}$, the most common symptom complained by respondent is headache $(15.44 \%)$, poor appetite $(8.45 \%)$, and unhappy (8.1\%) [25-30].

Based on the research findings the study concludes that the community has lack of awareness towards the cause and treatment of mental illness, epilepsy and it reveals that most of the people faced stressful life events consequently leading to higher prevalence of suicidal ideation. The study also identifies the Khat and alcohols are the most commonly used substance. The study also recommends the following prioritized problems in the community that needs interventions. Which includes Lack of awareness towards mental illness (78.4\%), Lack of awareness towards epilepsy (41.75\%), Presence of common mental disorders (6.76\%),Prevalence of stressful life event (34.87\%) and Prevalence of substance use (alcohol 31.44\%) [31-38].

\section{References}

1. Amare Deribew, Yonas Shiferaw, Tamirat (2015) Mental health problems perceived by a community in Agaro town 19(2).

2. Abebaw Fekadu, Girmay Medhin, Medhin Selamu, Maji Hailemariam, Atalay Alem, et al. (2014) Prevalence of common mental disorder.

3. Anteneh Messele Birhanu, Telake Azele bisetegn, Solomon Meseret wold yohanis (2014) High prevalence of substance use and associated factors among high school adolescents in Woreta Town, Northwest Ethiopia: multi-domain factor analysis. BMC Public Health 14: 1186.

4. Asmamaw Hailu, Prevalence and predictors of chat chewing among school going adolescents.

5. Bentley KJ (1994) Supports for community based mental health care; an optimistic view of federal legislation. Health Soc Work 19(4): 288294.

6. Binyam Negussie, Melake Damena, Gudina Egata (2010-2011) The prevalence of substance use. 
7. 2008 Central statistical agency.

8. Dr Birgit Radke (2010) Community mental health guide line.

9. 2011 Ethiopian Demographic and health survey.

10. National Mental Health Strategy (2012/13-2015/16) Federal Democratic Republic of Ethiopia. Ministry of Health, Ethopia.

11. Getinet Ayano (2013) Assessment of perception, attitude and associated factors among residents of Hawassa, South Ethiopia.

12. Gonçalves DM, Stein AT, Kapczinski F (2008) Performance of the SelfReporting Questionnaire as a psychiatric screening questionnaire: a comparative study with Structured Clinical Interview for DSM-IV-TR Cad Saúde Pública 24(2): 380-390.

13. Health FDROEMO (2012/13-2015/16) National Mental Health Strategy. Federal Democratic Republic of Ethiopia, Addis Ababa, Health FDROEMO, Ethiopia.

14. Nieuwsma JA, Pepper CM, Maack DJ, Birgenheir DG (2011) Indigenous perspectives on depression in rural regions of India and the United States. Transcultural Psychiatry 48(5): 539-568.

15. Kedir Yimam, Yigzaw Kebele, Telake Azale (2013) Prevalence of common mental disorder and associated risk factor.

16. Lars Jacobsson, Charlotte Hanlon ,Atalay Alem (2008) Community based mental health care in Africa: mental health workers' views. World psychiatry 7(1): 54-57.

17. Minale Takela (2015) Depression and anxiety among epileptic patient

18. Mohammed M, Mengistie B, Dessie Y, Godana W (2013) Prevalence of Depression and Associated Factors among HIV Patients Seeking Treatments in ART Clinics at Harar Town, Eastern Ethiopia. J AIDS Clin Res 6: 474 .

19. Mulat Gedefa, Tesfaye Wolde, Gebremedhin Solomon (2012) Knowledge, Attitudes and Practices with respect to Epilepsy among Preparatory School Students in Mekelle city, Ethiopia. International Journal of Collaborative Research on Internal Medicine \& Public Health $4(3)$.

20. National Institute of Mental Health.

21. Patel V, Araya R, Chowdhary N, King M, Kirkwood B, et al. (2008) Detecting common mental disorders in primary care in India: a comparison of five screening questionnaires. Psychol Med 38(2): 221228

22. Porter R (2006) Madmen; Social History of Madhouses, Mad Doctors and lunatics. Stroud, Gloucestershire Tempus Publishing, UK.

23. Rackel Jenkins, Rank Nienda, Mars Okanji, Pius Kigamwa, david kiime (2012) He prevalence of common mental disorder and its Sociodemographic risk factors 9(5): 1810-1819.
24. Robert Kohn (2004) Builetine of the WHO 82: 858-866.

25. Shitaye Almu, Zerihun Tadesse, Paul Cooper c, Richard Hackett (2006) The prevalence of epilepsy in the Zay Society, Ethiopia--An area of high prevalence 15(3): 211-213.

26. Skapinakis, Stefanos Bellos, Sotirios koupidis, Ilias grammatikopoulos, Pavlos N Theodorakis Venetsanos, et al. ( 2013) Prevalence and socio demographic association of common mental disorders in a nationally representative sample of the general population of Greece. BMC Psychiatry 13: 163.

27. Szmukler, Thornicroft (2001) Text book of community psychiatry. Oxford. New York, USA.

28. Dejenie Habtewold T, Radie YT, Sharew NT (2015) Prevalence of depression among type 2 diabetes patients in Black lion general Hospital Addis Ababa, Ethiopia. Depress Res Treat, pp. 184902.

29. Tesfaye M, Hanlon C, Tasemma F, Prince M, Alem A (2014) Common Mental Disorder Symptoms among Patients with Malaria Attending Primary Care in Ethiopia: A Cross-Sectional Survey. PLoS ONE 9(9): e108923.

30. V Mung'ala Odera S White, R Meehan, GO Otieno, P Njuguna, N Mturi, et al. (2008) Prevalence incidence and risk factors of epilepsy in older children in rural Kenya 17(5): 396-404.

31. (2006) WHO AIMS Assessment Instrument for Mental health systems, a report of the assessment of the mental health system in Ethiopia, p. 20-21.

32. (2001) WHO, Mental health; New understanding, new hope. The world Health Report. WHO, Geneva, Switzerland.

33. 2001 World Health Organization.

34. (2000) WHO International Consortium in Psychiatric Epidemiology. Cross- national comparisons of the prevalence and correlates of mental disorders. Bulletin of the World Health Organization 78: 413-426.

35. (2001) World Health Organization. The world health report 2001 Mental health: new understanding, new hope. Geneva: World Health Organization

36. (2007) World Health Organization press release Community Mental Health Services will lessen social exclusion, says WHO.

37. 2014 World Health Organization.

38. Zewdu, Abebe (2015) Common Mental Disorder among HIV Infected Individuals at Comprehensive HIV Care and Treatment Clinic of Debre Markos Referral Hospital, Ethiopia. J AIDS Clin Res 6: 420.

\section{Your next submission with Juniper Publishers} will reach you the below assets

- Quality Editorial service

- Swift Peer Review

- Reprints availability

- E-prints Service

- Manuscript Podcast for convenient understanding

- Global attainment for your research

- Manuscript accessibility in different formats

( Pdf, E-pub, Full Text, Audio)

- Unceasing customer service

Track the below URL for one-step submission https://juniperpublishers.com/online-submission.php 